\title{
Cultural management and government role
}

\author{
Edalat Nemati*
}

Technical University of Shamsipour, Tehran, Iran

\begin{tabular}{l}
\hline A R T I C L E I N F O \\
\hline Article history: \\
Received December 20, 2011 \\
Received in Revised form \\
March, 25, 2012 \\
Accepted 20 April 2012 \\
Available online \\
April 25 2012 \\
\hline Keywords: \\
Cultural Management \\
Civilization \\
Immaterial culture \\
Material culture
\end{tabular}

\section{A B S T R A C T}

Culture plays an important role on human lives and it has been in four ancient civilizations of China, Iran, Egypt and Greece. The civilization achievements are normally categorized in two different groups of material and immaterial. Practical experience of the material, social objective is called as a civilization and the mental aspect of spiritual experiences, spiritual and personal is called culture. The purpose of this research is to find a framework for cross-cultural management. First, we define the cultural planning and we review the existing cultural examples in Iranian society and try to provide an overall analysis. The paper also investigates the role of government on creating adaptive culture within the society and explains that government must act as leadership in creating value added culture.

(c) 2012 Growing Science Ltd. All rights reserved.

\section{Introduction}

During the past few decades, there have been increasing concerns with the cultural dimension to studies of logic, values, and aesthetics, and with the ontology and epistemology of the overall concept. Culture plays an important role in any civilization and a good understanding of civilization could help understand culture, more appropriately. According to Bagby (1958) civilization is the culture of cities and cities are defined as agglomerations of dwellings majority of whose inhabitants are not engaged in producing food and a civilization will be a culture in which cities are found. Blaha (2002) defined civilization as "Effective working definition (especially by archaeologists): a grouping of at least several thousand people with a common culture, usually a common language, usually a geographic locale, some significant (usually monumental) buildings and architecture, and a political structure that is not necessarily unified".

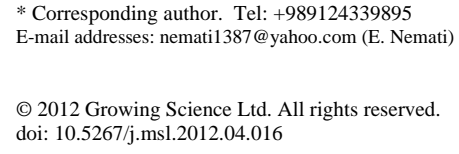


There are numerous research in medicine and in nutrition devoted to the concept of cultural terms but only few of them have focused on culture (Kroeber \& Kluckhohn, 1952). Development of human attitudes and dynamic development of his/her thinking has resulted in fundamental changes in all areas of human life, including culture. The recent advances in technology have changed culture, significantly and it has influenced all aspects of indigenous cultures. Today, many governmental agencies use "cultural management" to control these developments. Governments try implementing some special rules and regulations in their society for the management of cultural changes. They also use these rules and regulation to help present and future generations maintain their national cultural identity. Caligiuri (2006) explained that with respect to global leadership advances, managers differentially take advantage of a given intercultural training or developmental experience based on their individual aptitudes such as knowledge, skills, abilities, etc. Caligiuri attempted to offer the right people who are those with the requisite individual aptitudes and the right developmental opportunities to produce leaders who can effectively perform global leadership tasks and activities.

One of the most important characteristics in a society is to build creative nation and creative nation could contribute to nation, significantly. Mumford (2000) explained that technology is one the changes and global competition increases on a daily basis. Therefore, the success of any organizations depends on the ability to bring innovative products to market and innovation, on the other hand, depends on the generation of creative, new ideas. Mumford used the existing literature to conclude on the kind of human resource management strategies, which could enhance creativity. The author argued that organizations needed to consider multiple interventions including the individual, the group, the organization, and the strategic environment when they select interventions intended to enhance creativity.

Testa (2009) explained that continued globalization had been raising the level of diversity within hospitality organizations as well as the possibility that leaders would manage those from varying national cultures. Testa discussed that in the past, the research had found that cultural congruence between leaders and stakeholders from the same or various national cultures influenced a variety of variables including perceived leadership style, satisfaction and trust. Testa (2009) extended this line of research by studying the relationship between cultural congruence, perceived leadership style, leadermember exchange (LMX) and employee citizenship behaviors. Testa reported that cultural similarity impacted employee perceptions of LMX relations and organization citizenship behaviors, but not leadership style.

The primary purpose of this paper is to provide a general framework for cultural management, which could be used as socio-cultural law. We also explain cultural programming and investigate cultural evidences to find a comprehensive solution. To reach this goal we need to carefully study both management science as well as the concept of culture in society. In our study, we investigate the relationship between culture and management. We also study on how government can influence these two components.

First, we need to find a comprehensive definition of the concept of management. In fact, there are different definitions for this term. It can be defined as the act of uniting people together to reach desired aims and objectives using some resources, efficiently and effectively. Management consists of planning, organizing, leading, staffing or directing, and controlling a particular firm or a group of one or more people or attempts to accomplish an objective. Resourcing encompasses the deployment and manipulation of human resources, financial resources, technological resources and natural resources. Management solely is neither a science nor an art but it is more a kind of skill. In other words, management is an application of different scientific purposes under various conditions. Hence, in order to coordinate and synchronize the movement of spiritual and material culture and the arts community, we need to build an appropriate framework (Mumford,1974). 
The organization of this paper first presents details of different kinds of management in section 2 and section 3 offers necessary suggestions to build the framework. Finally, concluding remarks are given at the end to summarize the contribution of this paper.

\section{Cultural management}

Cultural management consists of two fields of science on one side and culture of science such as sociology, history, mental sociology, anthropology, politics, etc. The primary purpose of this kind of science is to train managers who are able to perform leadership role on cultural organizations. A cultural manager needs to have good skills on psychology, sociology, principles of education, philosophy, history, art and literature in addition to traditional management science. These people are normally responsible to find problem solution for different social chaos in organizations. In fact, they have the capability to provide appropriate solutions. They have different audiences and must provide appropriate solutions to meet different types of people in various ages. A cultural manager must provide assistance for a wide range of people with various opinions, there is often conflict of interest among people, and this makes decision to be harder to make. A successful manager must have a good perception on the culture and do his/her best to offer suitable efforts, which could fit the society. Note that a conflict in society could end to a chaos in society since different ethnic groups are sensitive on certain issues such as language, religion, etc (Thomas, 2008).

\subsection{Material and immaterial culture}

Sociologists have divided the culture into two parts of material and immaterial but many believe this classification is somewhat subjective, and there is no virtual separation between these two concepts since immaterial aspects of culture are reflected within the material specifications (Harrington, 2008).

\subsubsection{Material culture}

This type of culture is described as tangible and visible type of events, which appear in a society and it can be measured using quantitative and scientific methods. Examples of this type culture include industry, tools and their products, clothes, books, paintings, etc. In other words, all material achievements in the history are categorized in this group. The material culture was gradually changed and instead of focusing on materials, it refers to all aspects of human lives, which influence on production, either directly or indirectly. According to Mumford $(1949,1950)$ technology is not out of a culture but it is a portion of itself since all components of technology do not advance at the same time, some of them are more advance than others. For instance, mass media applications such as TV or Internet facilities are advancing very quickly or some of the facilities used in medical care have recently changes, significantly. Since economical indices play important role on people's perception and they are the basis for separation of different economies, there is more attention devoted to material culture more than other components of culture (Hughes \& Hughes, 1990).

Although material culture is more important for any kind of investigation on culture but it maintains some contradictions components. In fact, there are some correlations between material and immaterial culture and these are two sides of culture, which must be studied together.

\subsubsection{Immaterial culture}

There are different kinds of intangible assets among a nation, which have been created during the history of the nation, such as religion, science, customs and traditions, laws and regulations. These assets cannot be measured or they are not tangible but we can easily understand them. Immaterial culture is the core of a national culture, this framework empowers the soul of nations, and it determines the actual power. Immaterial culture in any nation contains some evidences on spirituality, political believes, theoretical aspects of science, heroes, etc. 


\section{Planning suitable cultural planning, criteria and stages}

One of the most important issues on planning cultural planning is to set an appropriate synergy among desirable outcomes with national and traditional culture. Desirable immaterial cultural will be resulted only through a good planning. In other words, we need to have a schedule and precise plan to reach immaterial cultural changes. In this stage, government plays an important role on influencing cultural changes, significantly. There are some evidences, which criticize the government involvement and suggest that government must stay away from the cultural changes.

It seems that government can have both positive and negative influences on cultural management. Government needs to provide leadership in macro scale and details of rules and regulations must be transferred to non-governmental organizations. However, many believe that government does not have to act or be involved with cultural management and any change on culture must be executed through the nation. This could be a fact among the nations where government is not elected by people but when the government is officially chosen by the people themselves, any rules and regulations will be in favor of people. In such circumstances, people will benefit from government's decisions and there is no need to worry about the consequences. When we say government must have an important role on cultural management, it does not mean that government must dominate all aspects of cultural management. The government could set macro-economical rules and regulations and lead the community to develop values based on people believes.

\section{Conclusion}

In this paper, we have presented an overview on different aspects of cultural management. We have explained that there are two groups of material and immaterial cultures and these two components influence each other, significantly. The study has provided a detailed discussion on why government must be involved in cultural planning in society. The paper also explained that government needed to act in macro scale especially in cases where government has a big support among the nation. In such circumstances, there will be a better rules and regulations and people contribute to culture in different aspects.

\section{References}

Bagby, P. (1958). Culture and History. University of California Press.

Blaha, S. (2002). The Life Cycle of Civilizations. Auburn, NH: Pingree-Hill Publishing.

Caligiuri, P. (2006). Developing global leaders. Human Resource Management Review, 16(2), 219228

Kroeber, A.L., \& Kluckhohn, C. (1952). A Critical Review of Concepts and Definitions. Vintage Books, New York.

Harrington, A. (2008). A Sociology of the Demonic? Alfred Weber's Conception of 'Immanent Transcendence'. Journal of Classical Sociology, 8(1), 89-108.

Hughes, T. P., \& Hughes, A. C. (1990). Lewis Mumford: Public Intellectual. New York: Oxford University Press. ISBN 019506173X.

Mumford, L. (1949). The Sky Line: The Quick and the Dead. The New Yorker, 24 (46), 60-65.

Mumford, L. (1950). The Sky Line: Civic Virtue. The New Yorker, 25(50), 58-63.

Mumford, Lewis (1974). Enough energy for life \& the next transformation of man. CoEvolution Quarterly (Sausalito, CA: POINT Foundation), 1(4), 19-23.

Mumford, M.D. (2000). Managing creative people: Strategies and tactics for innovation. Human Resource Management Review, 10(3), 313-351.

Targowski, A. (2004). A grand model of civilization. Comparative Civilizations Review, 51, 81-106.

Testa, M.R. (2009). National culture, leadership and citizenship: Implications for cross-cultural management. International Journal of Hospitality Management, 28(1). 78-85

Thomas, D.C. (2008). Cross-Cultural Management: Essential Concepts. $2^{\text {nd }}$ ed., Sage Publications. 